medical practice. Unless the position has changed substantially since the summer, which we doubt, our findings do not suggest a consistent accounting basis for the NHS reforms due in April.

C KELLEHER

P J RODERICK

T W MEADE

MRC Epidemiology and Medical Care Unit, Northwick Park Hospital,

Harrow HAl 3UJ

\section{Stopping the pill}

SIR,-Mr G E Robinson and colleagues report evidence clearly in favour of the combined contraceptive pill being stopped at least four weeks before major surgery. ' How, in practice, are we to achieve this? Patients may wait many months for major surgery and may receive only a few days notice of an admission date. Worse still, they may then follow instructions to ring to confirm that a bed is available on the morning of admission, only to find the bed is not available.

As long as patients are kept in such uncertainty up to the last minute we have no hope of diminishing this particular risk factor for their surgery. A present any attempt generally to advise women to stop the pill before major surgery must inevitably result in the greater risk of unwanted and unplanned pregnancies because of the unpredictability of the date of admission.

RUTH BOOKER

St John's Health Centre

Twickenham TW1 3PA

1 Robinson GE, Burren T, Mackie IJ, et al. Changes in haemostasis fter stopping the combined contraceptive pill: implication for major surgery. BMF 1991;302:269-71. (2 February.)

\section{Antitetanus boosters}

SIR, - Although in general I agree with Dr David Elliman regarding tetanus boosters before foreign holidays, ${ }^{\prime}$ I think that immunisation may be indicated before travel if there is a risk of unsterile needles being used for boosters after injury. Hepatitis B has been transmitted in this way and there may be a risk of HIV infection.

Travellers visiting areas with this risk should either carry a sterile needle and syringe pack or have a pre-emptive booster if more than five years have elapsed since the last dose.

J M STEWART

British Airways Medical Service to Travellers Abroad,

London WC1A 2LA

1 Elliman D. Any questions. BMf 1991;302:285. (2 February.)

\section{Prescribing psychotropic drugs to children and adolescents}

SIR, - I was surprised that Dr Sue Adams assumed that her study ${ }^{1}$ was the first to look at prescribing psychotropic drugs to children and adolescents. Quinn looked at prescribing psychoactive drugs in a province of Canada ${ }^{2}$ and Ellinger evaluated it in Germany. ${ }^{3}$

S J Dunkley and I have looked at the use of tricyclic antidepressive agents in childhood and adolescent disorders, including mental handicap, and our results have some interesting similarities with those of Dr Adams. Her three month period prevalence of $68 \%$ for prescription of psychotropic drugs for children and adolescents by psychiatrists compares with our figure of $89 \%$ acknowledgement of such prescriptions by child and adolescent psychiatrists. We surveyed 238 practising British specialists; $84 \%$ of them also stated that they used antidepressive agents in their current practice.

Three quarters of prescribers would use antidepressive drugs for childhood depression despite continuing dispute within the specialty concerning the nosology and phenomenology of depression. Of those prescribing antidepressive drugs, $90 \%$ stated that they used the drugs for depressed adolescents; this approaches the pattern that obtains in adult practice.

A surprisingly high figure of $79 \%$ of child psychiatrists would consider using antidepressive drugs in nocturnal enuresis, given the strong developmental component of this condition-yet the majority $(52 \%)$ qualified their response by stating that they would prescribe them only very rarely, adding comments that they would be used only as a temporary measure to allow the child (and family) some respite before behavioural family work could start or to cover enuretic children while on holiday during treatment. No prescribers stated that they would use drugs as a sole treatment for either nocturnal enuresis or depression.

This survey also showed that two thirds of child psychiatrists were not prepared to accept nonspecialist prescription of psychotropic drugs to children or adolescents.

DAVID BRAMBLE

Department of Psychiatry

University of Leicester

Leicester LE2 7LX

1 Adams S. Prescribing of psychotropic drugs to children and adolescents. BMF 1991;302:217. (26 January.)

2 Quinn DMP. Prevalence of psychoactive medication in children and adolescents. Can $\mathcal{Y}$ Psychiatry 1990;31:575-80.

3 Ellinger TJ. Prevalence of psychotropic medication in childhood and adolescence in the Federal Republic of Germany.

Pharmacopsychiatry 1990;23:38-44.

\section{Psychologists warn against community charge}

SIR, - I can see no reason why a person certified as suffering from "severe mental impairment" according to the Local Government Finance Act 1988 should be considered for detention under the Mental Health Act 1983 as stated in the news item by Dr Alison Walker. ${ }^{1}$ There could be confusion among patients and carers but not, I think, among well informed professionals about the use of this term in the two acts. They use two different criteria: impairment of social functioning and intelligence is shared by both, but seriously irresponsible conduct and abnormally aggressive behaviour are criteria found only in the Mental Health Act. Severe mental impairment in this act is "a state of arrested or incomplete development of mind" whereas the Local Government Finance Act states "however caused," to include mentally handicapped, brain damaged, mentally ill, and elderly mentally ill people.

No doubt these definitions raise questions of whether people could lose their civil liberties if certified as mentally impaired according to the Local Government Finance Act, but John Reed stated in a "Dear Doctor" letter (PL/CO(90)7) that "the exemption of the Community Charge because of severe mental impairment itself would not affect the right to vote or to be included in the Electoral Roll." What is required to vote is the capacity to understand the local issues and exercise a stake in the spending decisions of the local authority. I do not understand why someone should have the right to vote, if certified as mentally impaired on the basis of the definition in the Local Government Finance Act, and be exempted from paying the community charge, which is intended to give the chargepayer a direct stake in spending decisions.

The Local Government Finance Act fails to provide adequate guidelines for the diagnosis of severe mental impairment but the certifying doctor, if in doubt, is expected to get information and advice from appropriate colleagues. A cut off point of IQ 54 would exclude many people who may suffer from severe social and emotional handicaps and just manage to score over 54 in the IQ tests.

The term severe mental impairment nowadays is used only for purposes set out in the Mental Health Act 1983. The preferred term is learning difficulty or disability as most professionals feel that severe mental impairment is somewhat degrading. While we are getting away from using this term we are forced to use it in a wider scale according to the Local Government Finance Act to include other mentally disordered people.

People who are living in social services hostels and hospitals are exempted from the community charge. Most of these people may not qualify to be certified as they may be suffering from either social impairment or intellectual impairment, but not necessarily both. A recent communication from Duncan Nichol says that more people are able to choose to remain in or return to their own homes, whether during periods of temporary crisis or when they need long term support. ${ }^{2}$ Contrary to the spirit of this, people who are suffering from either of the two handicaps who are cared for in the community are expected to pay the community charge. Even if they claim maximum rebate I think it is morally wrong to say that they should pay the $20 \%$ for no fault of theirs except that they happen to have a caring relative.

I have suggested that the term severe mental impairment should be withdrawn from the definition in the Local Government Finance Act and substituted by "mental disability" or other similar, less offensive terms. ${ }^{3}$ I also suggested altering the phrase "severe impairment of intelligence and social functioning" in the definition to "severe impairment of intelligence and/or social functioning." "4

East Berkshire Health Authority,

K NADESALINGAM Bracknell RG12 4EP

1 Walker A. Psychologists warn against community charge. $B M \mathcal{J}$ 1991;302:135. (19 January.)

2 Nicol D. Caring for people: community care in the next decade and beyond: questions and answers. London: NHS Managemen Executive, 1989. (EL(89)MB202.)

Nadesalingam K. Local Government Finance Act 1988-menta impairment and poll tax. Psychiatric Bulletin 1990;14:239-40.

4 Nadesalingam K. Local Government Finance Act 1988-menta impairment and poll tax. Psychiatric Bulletin 1990;14:747.

\section{Modified shooting sticks}

SIR,-Like Dr Jonathan Kerr I can testify to the usefulness of "suburban shooting sticks,", and I am pleased to confirm that they are easily obtainable ready made with a rubber ferrule for suburban use. It would be a pity if potential users were put off by believing that sawing and welding of a spiked rural model were required.

Christian Medical Fellowship,

ANDREW FERGUSSON

London SE1 8XN

1 Kerr J. [Modified shooting stick.] BMf 1991;302:424 (16 February.)

\section{Correction}

\section{Retinoblastoma linked with Seascale}

An editorial error occurred in this letter by $\mathrm{Dr} W$ Foulkes and others (16 February, p 409). Part of the third paragraph should read "it should be possible . . to find out in the case of the child with bilateral disease whether the allele retained in the tumour, which sustained the first mutation, did indeed arise from the mother. The other allele, inherited from the father, is normal and it is the somatic loss of this allele that allows the tumour to occur." 